ARTICLE

\title{
Pregnancy and the kidneys
}

\author{
N Wearne, BA Med Sci (University of Sydney), MB ChB Honours (University of Sydney), FCP (SA), Cert Nephrology (SA) \\ Division of Nephrology and Hypertension, Department of Medicine, Faculty of Health Sciences, Groote Schuur Hospital and University of \\ Cape Town, South Africa
}

Corresponding author: $N$ Wearne (nicola.wearne@uct.ac.za)

Renal disease in pregnancy may cause a feeling of trepidation, even in the most experienced physician. However, before disease can be established, it is important to understand the substantial physiological changes that may occur during a normal pregnancy. Renal disease may take several forms and pregnancy may be the first medical review for women with a previously undiagnosed renal problem. Patients may have pre-existing renal disease, e.g. diabetic nephropathy. Additionally, women with renal transplants and renal diseases, e.g. lupus nephritis, require immunosuppression. Hypertensive disorders of pregnancy, including pre-eclampsia, are the commonest medical complications in pregnancy, and remain the most prevailing direct cause of maternal mortality in South Africa (SA). Both pre-existing hypertension and renal disease increase the risk of pre-eclampsia, which predisposes to preterm delivery, and maternal morbidity and mortality.

Pregnancy outcomes in renal disease are determined by baseline creatinine levels, hypertension and degree of proteinuria. The risk of progression of chronic kidney disease increases as renal function worsens. In SA, this is complicated by restricted access to dialysis in the state sector. To ensure the best outcome for mother and child, pre-pregnancy counselling and review of medication are essential. Renal patients and those with hypertension are at high risk of complications, and regular antenatal assessments by a multidisciplinary team are required to monitor blood pressure, proteinuria, diabetes control and fetal wellbeing.

S Afr Med J 2014;104(9):642. DOI:10.7196/SAMJ.8765

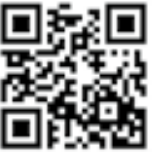

Renal disease in pregnancy may cause a feeling of trepidation, even in the most experienced physician, and may take several forms. Pregnancy may be the first medical review for women with a previously undiagnosed renal problem. Patients may have pre-existing renal disease, e.g. diabetic nephropathy. Additionally, women with renal transplants and renal diseases, e.g. lupus nephritis, require immunosuppression. Pregnancy outcomes in renal disease are determined by baseline creatinine levels, hypertension and degree of proteinuria. The risk of progression of chronic kidney disease (CKD) and maternal and fetal complications increases as the renal function worsens, and patients need to be counselled, preferably prior to conception. Pre-existing renal disease predisposes to pre-eclampsia, a condition occurring in up to $5 \%$ of pregnancies, making it one of the most common complications of pregnancy. A multidisciplinary team approach involving a physician/nephrologist and an obstetrician is essential to assess and care for pregnant women with kidney disease.

\section{Normal physiological adaptations of pregnancy}

The kidneys increase in length $(1-2 \mathrm{~cm})$ and volume (70\%) with dilation of the calyces, renal pelvis and ureters, features which are more prominent on the right. By the third trimester, $80 \%$ of women show evidence of hydronephrosis, which predisposes to urinary stasis, increasing the risk of urinary tract infections. ${ }^{[1]}$ There is hormonal dilatation of the systemic blood vessels, leading to a decrease in systemic vascular resistance and a physiological lowering of blood pressure, especially during the first and second trimesters. Thereafter, there is a steady return of blood pressure to pre-pregnancy levels until term.
Plasma volume increases significantly, leading to a 30 - 50\% increase in cardiac output and resulting in a steady increase in renal blood flow ( $50 \%$ by the mid-second trimester). This increases the glomerular filtration rate (GFR) and gives rise to frequency and nocturia, resulting in decreased creatinine blood levels. The increased vascularity of the kidneys makes a renal biopsy beyond 32 weeks risky. Despite the increase in renal blood flow, the pressure within the glomerulus remains unaltered owing to compensatory effects on the afferent and efferent arteriole, but this only occurs in a normal kidney. Any pre-existing disease in the kidney will be accelerated, often with deterioration in renal function.

Pregnancy also affects the renal tubules. There is decreased reabsorption of glucose and bicarbonate, leading to glycosuria and bicarbonaturia. Despite the loss of bicarbonate, there is a persistent alkalosis owing to an increased respiratory rate. There is hypercalciuria, although the risk of renal stones is not increased as inhibitors of stone formation also increase. It is also common to find mild proteinuria, $<300 \mathrm{mg} / \mathrm{d}$, which may remain up to 6 months postpartum. Isolated pyuria is common and disappears by 3 months postpartum. Serum sodium may decrease by $4-5 \mathrm{mEq} / \mathrm{L}$ and serum osmolality falls to a new osmotic setpoint of about $270 \mathrm{mOsm} / \mathrm{kg}$.

Important renal adaptations in pregnancy

- Increase in kidney size $1-2 \mathrm{~cm}$

- Dilatation of the urinary collecting system

- Increase in renal blood flow

- Increase in glomerular filtration rate

- Decrease in creatinine

- Glycocosuria and bicarbonaturia

- Decrease in plasma sodium and osmolality 


\section{Estimating glomerular filtration rate in pregnancy}

The modification of diet in renal disease (MDRD) is a creatininebased formula that measures GFR. It has become a standard clinical method used to estimate renal function in patients with CKD. The use of this formula has not been well studied in the pregnant population and guidelines for its use exclude pregnant women, ${ }^{[2]}$ because creatinine falls in pregnancy owing to a pregnancy-induced increase in GFR and haemodilution from plasma expansion. The MDRD formula is also known to be inaccurate once the GFR is $>60$ $\mathrm{ml} / \mathrm{min} / \mathrm{m}^{2}$, even in non-pregnant women. This inaccuracy is more pronounced in pregnancy. ${ }^{[3]}$ Weight-based formulas, such as those used in the Cockroft-Gault method, are likely to overestimate GFR because the increased body weight in pregnancy does not typically reflect increased muscle mass or creatinine production. ${ }^{[4]}$ Given this, 24-hour urine collection for creatinine clearance remains the gold standard for GFR estimation in pregnancy.

\section{Estimating proteinuria in pregnancy}

Proteinuria needs to be measured first to monitor pre-existing proteinuria, which may increase substantially during pregnancy. The protein-creatinine ratio (PCR) is the preferred method for quantitating proteinuria in the non-pregnant state ${ }^{[5]}$ and its use is recommended to monitor pre-existing proteinuria during pregnancy. The second indication is for the diagnosis of pre-eclampsia, which is defined as the new onset of hypertension (blood pressure (BP) $>140 / 90 \mathrm{mmHg}$ ) and proteinuria (>300 $\mathrm{mg}$ protein in a 24-hour urine collection) after 20 weeks' gestation. ${ }^{[6]}$ Although there are limitations to 24-hour urine collections, the use of PCR for the diagnosis of pre-eclampsia has been controversial, with discordant conclusions compared with 24 -hour urine collections. ${ }^{[7]}$

\section{Specific diseases of the kidney Hypertensive disorders, including pre-eclampsia}

Hypertensive disorders of pregnancy are the commonest medical complications in pregnancy, and remain the most prevailing direct cause of maternal mortality in SA. ${ }^{[8]}$ In the UK, $3-5 \%$ of pregnant women have hypertension that predates conception. ${ }^{[9]}$ It is more common in advanced maternal age, obesity and blacks. ${ }^{[10]} \mathrm{A}$ secondary cause should be excluded if appropriate. About $22-25 \%$ of women with pre-existing hypertension are likely to develop pre-eclampsia. ${ }^{[1]}$ Pregnancy-induced hypertension is defined as a BP $>140 / 90 \mathrm{mmHg}$ arising after 20 weeks of gestation and returning to normal within 6 weeks postpartum. ${ }^{[6]}$ Pre-eclampsia is a multisystem disorder that is commonly associated with oedema and hyperuricaemia. It is a leading cause of maternal mortality and morbidity in developed ${ }^{[12]}$ and developing countries, where it continues to claim the lives of $>60000$ mothers every year. ${ }^{[13]}$

Pre-eclampsia appears to be initiated by abnormal implantation of the placenta, leading to hypoperfusion and ischaemia. There is accumulating evidence supporting the release of several placental anti-angiogenic factors including soluble fms-like tyrosine kinase-19 (sFlt1) and its synergist, soluble endoglin (sEng). These antiangiogenic factors are induced or exacerbated by placental ischaemia, with sFlt1 being a circulating antagonist to both vascular endothelial growth factor (VEGF) and placental growth factor. Circulating VEGF is mopped up by sFlt1to prevent the former's protective effects on the endothelium. When administered to pregnant rats, sFlt1 and sEng produce a syndrome resembling that of HELLP (haemolysis, elevated liver enzymes, and low platelets). ${ }^{[14,15]}$ Subsequent studies have demonstrated the role of these anti-angiogenic factors in the pathogenesis of pre-eclampsia in humans. ${ }^{[16-18]}$
Clinically, vascular endothelial dysfunction and microangiopathy are present in the mother, but not in the fetus. The predominant target organ may be the brain (seizures or eclampsia), the liver (HELLP syndrome), or the kidney (glomerular endotheliosis and proteinuria). Predisposing factors include pre-existing hypertension, CKD, obesity, diabetes mellitus, thrombophilias, and multiple gestations. ${ }^{[19]}$ These women may be more susceptible to endothelial dysfunction and hence more responsive to anti-angiogenic factors.

Screening for pre-eclampsia has the greatest impact on clinical outcomes, but to date there is no effective preventive treatment. Although two large meta-analyses have suggested a small, but significant, overall benefit in patients treated with aspirin, ${ }^{[20,21]}$ the delivery of the fetus is currently the only definitive treatment.

Considerable evidence suggests that pre-eclampsia predisposes women to late cardiac and vascular diseases ${ }^{[22]}$ and also increases the risk of subsequent CKD. The risk is greater if a pre-eclamptic pregnancy results in the birth of a low-birth-weight or preterm infant or if pre-eclampsia occurs in more than one pregnancy. ${ }^{[23]}$

\section{Chronic kidney disease in pregnancy}

Women with CKD who become pregnant are at increased risk for adverse maternal and fetal outcomes, including a rapid decline in renal function, intrauterine grown retardation, perinatal mortality and pre-eclampsia. ${ }^{[24,25]}$ The major determinants of outcome are pre-existing proteinuria, hypertension, urinary tract infection and degree of renal dysfunction. Obstetric outcomes are also partly related to the level of available neonatal care. Very importantly, maternal renal function may decline irreversibly proportional to the level of pre-existing dysfunction. In a SA setting, this is an important consideration as access to dialysis is limited in the state sector.

Maternal renal function declines proportional to the level of pre-existing renal dysfunction ${ }^{[24,26]}$

- Creatinine $<123 \mu \mathrm{mol} / \mathrm{L}$ : considered safe

- Creatinine $130-170 \mu \mathrm{mol} / \mathrm{L}: 40 \%$ have deterioration in renal function, of whom half recover

- Creatinine $>176 \mu \mathrm{mol} / \mathrm{L}$ : two-thirds have an accelerated decline in renal function and one-third require dialysis

The stress of increased renal blood flow and inability of the glomerulus to regulate intraglomerular pressure, which normally remains unaltered during pregnancy, may exacerbate renal damage in pre-existing disease.

\section{Managing dialysis and renal transplant patients}

CKD is generally characterised by menstrual disturbances and infertility, and is reversed by transplantation but not by dialysis. ${ }^{[27]}$ Although conception in patients on dialysis is unusual, it is not impossible, and adequate contraception remains important. When pregnancy does occur, it needs to be co-managed by a nephrologist and an obstetrician as significant changes in management are required to improve maternal and neonatal outcomes. Transplant patients should also be co-managed as immunosuppressive drugs may need to be altered and their plasma levels will need to be carefully monitored. Pregnant women who have a transplanted kidney with renal dysfunction should be considered in the same way as other patients with CKD.

\section{Pregnancy-induced acute kidney injury}

Acute kidney injury (AKI) in pregnancy may be caused by any of the disorders leading to renal failure in the general population, e.g. 
acute tubular necrosis (ATN) due to infection, glomerulonephritis or drug toxicity. There are, however, pregnancy-related complications characteristic of each trimester that can result in renal failure. ${ }^{[28,29]}$ Early in pregnancy the most common problems are pre-renal disease due to hyperemesis gravidarum or ATN following a septic abortion. In the second and third trimesters, pregnancy-specific conditions, e.g. pre-eclampsia, HELLP syndrome, acute fatty liver of pregnancy, haemolytic-uraemic syndrome and thrombotic thrombocytopenic purpura, can be complicated by acute renal failure. At delivery, placental abruption can be associated with severe ATN and bilateral cortical necrosis. The management of AKI is similar to that in a non-pregnant patient, with fluid management being especially important, particularly in the context of pre-eclampsia, as the vascular endothelium is very leaky. Potential nephrotoxins such as the nonsteroidal anti-inflammatory drugs (NSAIDs) and aminoglycosides should be used with caution throughout the pregnancy.

\section{Managing the complicated patient Diabetic nephropathy}

Diabetic nephropathy is frequently encountered during pregnancy. Prepregnancy counselling is important, as obstetric and renal outcomes are determined by the degree of peripartum CKD. There is no increased risk of overt nephrophathy or end-stage renal disease in women with normal renal function at conception. ${ }^{[30]}$ However, diabetic nephropathy is associated with a 2 - 4 -fold increased risk of pre-eclampsia, preterm delivery and perinatal death. ${ }^{[3]}$ Management includes low-dose aspirin from the first trimester to reduce the risk of pre-eclampsia, regular renal function monitoring, good BP control and tight glycaemic control.

\section{Lupus nephritis}

Women with lupus nephritis should be advised to conceive after a 6-month period of quiescent disease. Predictors of poor obstetric outcomes include active disease at conception and early pregnancy, $>0.5 \mathrm{~g}$ protein $/ 24 \mathrm{~h}, \mathrm{CKD}$ stage $>3$, hypertension and antiphospholipid antibodies. There is also an increased risk of pre-eclampsia.

Extra-renal disease flare-ups are more common in the second and third trimesters, and postpartum flare-ups have been described. ${ }^{[32]}$

Flare-ups can be managed with corticosteroids. Maintenance therapy with azathioprine and hydroxychloroquine is considered safe. Tacrolimus and cyclosporin can be used in pregnancy with therapeutic drug level monitoring. Differentiating between a flareup of lupus nephritis and pre-eclampsia may be challenging. A low $\mathrm{C} 3 / \mathrm{C} 4$, a rising double-stranded DNA (dsDNA) and an active urine sediment with red cell casts are suggestive of recurrence of lupus.

\section{Drugs and the kidney}

Methyldopa is the first-line agent of choice to treat hypertension in pregnancy and has a well-documented safety profile, ${ }^{[33,34]}$ while the calcium channel blocker, nifedipine, ${ }^{[35]}$ and the selective $\alpha_{1}$ - and non-selective $\beta$-adrenergic receptor-blocker, labetalol, also appear to be safe. ${ }^{[36]}$ Diuretics are generally not recommended as they can theoretically compromise the pregnancy-associated increase in plasma volume, although outcome data have not supported these concerns. ${ }^{[37]}$ Angiotensin-converting enzyme (ACE) inhibitors are teratogenic and can cause renal dysgenesis, oligohydramnios, calvarial and pulmonary hypoplasia, intrauterine growth restriction, and neonatal renal failure, leading to death of the fetus as early as the first trimester ${ }^{[38,39]}$ Similar anomalies have been reported with angiotensin II receptor blockers (ARBs). ${ }^{[40]}$ ACE inhibitors and ARBs should be discontinued prior to conception, with appropriate birth control measures while on these agents.
Calcineurin inhibitors, glucocorticosteroids and azathioprine are the mainstay of safe immunosuppressive therapy in pregnant transplant recipients and lupus patients. Mycophenolate mofetil has been reported to cause developmental toxicity, malformations, and intrauterine death in animals, with growing evidence confirming its teratogenic effects in humans. The drug should be discontinued 6 weeks before conception.

\section{Conclusion}

Because there are substantial physiological changes that occur in a normal pregnancy, it is necessary to understand these in order to determine whether the kidney developed disease during pregnancy. Both pre-existing hypertension and renal disease increase the risk of adverse pregnancy outcomes and increase the risk of pre-eclampsia, which predisposes to preterm delivery. Pregnancy in a patient with CKD may cause progression of renal failure, and in the SA setting this is complicated by restricted access to dialysis in the state sector. To ensure the best outcome for mother and child, pre-pregnancy counselling is essential. Attention must be paid to the numerous teratogenic drugs that are commonly used to treat hypertension and the immunosuppression necessary to treat renal transplant recipients and those with glomerulonephritis (e.g. lupus nephritis). Patients with renal disease and hypertension are at high risk of complications and regular antenatal assessments are required that should involve a multidisciplinary team to monitor $\mathrm{BP}$, proteinuria, diabetic control and fetal wellbeing .

\section{References}

1. Rasmussen PE, Nielsen FR. Hydronephrosis during pregnancy: A literature survey. Eur J Obstet Gynaecol Reprod Biol 1988;27:249-259. [http://dx.doi.org/10.1016/0028-2243(88)90130-X]

2. Levey AS. Use of glomerular filtration rate measurements to assess the progression of renal disease. Semin Nephrol 1989;9:370-379.

3. Smith MC, Moran P, Ward MK, Davison JM. Assessment of glomerular filtration rate during pregnancy using the MDRD formula. Br J Obstet Gynaecol 2008;115:109-112. [http://dx.doi.org/10.1111/j.14710528.2007.01529.x]

4. Alper AB, Yi Y, Webber LS, et al. Estimation of glomerular filtration rate in preeclamptic patients. Am J Perinatol 2007;24:569-574. [http://dx.doi.org/10.1055/s-2007-986697]

5. Eknoyan G, Hostetter T, Bakris GL, et al. Proteinuria and other markers of chronic kidney disease: A position statement of the National Kidney Foundation (NKF) and the National Institute of Diabetes and Digestive and Kidney Diseases (NIDDK). Am J Kidney Dis 2003;2:617-622. [http://dx.doi.org/10.1016 S0272-6386(03)00826-6]

6. American College of Obstetricians and Gynecologists. Diagnosis and management of preeclampsia and eclampsia. Int J Gynaecol Obstet 2002;77:67-75.

Price CP, Newall RG, Boyd JC. Use of protein: Creatinine ratio measurements on random urine Price CP, Newall RG, Boyd JC. Use of protein: Creatinine ratio measurements on random urine
samples for prediction of significant proteinuria. A systematic review. Clin Chem 2005;51:1577-1586. [http://dx.doi.org/10.1373/clinchem.2005.049742]

8. National Committee on Confidential Enquiries into Maternal Deaths. Saving Mothers 2005-2007: Fourth National Committee on Confidential Enquiries into Maternal Deaths. Saving Mothers 2005-2007: Fourth
Report into Maternal Deaths in South Africa. Expanded Executive Summary. Pretoria: Department of Health, 2009.

9. Magee LA, Ornstein MP, von Dadelszen P. Fortnightly review: Management of hypertension in pregnancy. Br Med J 1999;318:1332-1336. [http://dx.doi.org/10.1136/bmj.318.7194.1332]

0. Sibai BM. Treatment of hypertension in pregnant women. N Engl J Med 1996;335:257-265. [http:// dx.doi.org/10.1056/NEJM199607253350407]

1. Chappell LC, Enye S, Seed P, et al. Adverse perinatal outcomes and risk factors for preeclampsia in women with chronic hypertension: A prospective study. Hypertension 2008;51:1002-1009. [http:// dx.doi.org/10.1161/HYPERTENSIONAHA.107.107565]

12. Centre for Maternal and Child Enquiries. Saving mothers' lives: Reviewing maternal deaths to make motherhood safer: 2006-2008. The Eighth Report on Confidential Enquiries into Maternal Deaths in the United Kingdom. Br J Obstet Gynaecol 2011;118(Suppl 1):1-203. [http://dx.doi.org/10.1111/ in the United Kingdom.

13. World Health Organization (WHO). World Health Report 2005: Make Every Mother and Child Count. Geneva: WHO, 2005:63.

14. Gu Y, Lewis DF, Wang Y. Placental productions and expressions of soluble endoglin, soluble fms-like tyrosine kinasereceptor-1 and placental growth factor in normal and preeclamptic pregnancies. J Clin Endocrinol Metab 2007;93:260-266. [http://dx.doi.org/10.1210/jc.2007-1550]

15. Venkatesha S, Toporsian M, Lam C, et al. Soluble endoglin contributes to the pathogenesis of preeclampsia. Nature Medicine 2006;12(6):642-646. [http://dx.doi.org/10.1038/nm1429]

16. Levine RJ, Lam C, Qian C, et al. Soluble endoglin and other circulating antiangiogenic factors in preeclampsia. N Engl J Med 2006;355:992-1005. [http://dx.doi.org/10.1056/NEJMoa055352]

17. Robinson CJ, Johnson DD. Soluble endoglin as a second-trimester marker for preeclampsia. Am Obstet Gynecol 2007;197(2):174e1-5.

18. Rana S, Karumanchi SA, Levine RJ, et al. Sequential changes in antiangiogenic factors in early pregnancy and risk of developing preeclampsia. Hypertension 2007;50:137-142. [http://dx.doi. org/10.1161/HYPERTENSIONAHA.107.087700]

19. Walker JJ. Pre-eclampsia. Lancet 2000;356(9237):1260-1265. [http://dx.doi.org/10.1016/S01406736(00)02800-2]

20. Askie LM, Duley L, Henderson-Smart DJ, Stewart LA. Antiplatelet agents for prevention of preeclampsia: A meta-analysis of individual patient data. Lancet 2007;369:1791-1798. [http://dx.doi. org/10.1016/S0140-6736(07)60712-0] 
21. Duley L, Henderson-Smart DJ, Knight M, King JF. Antiplatelet agents for preventing pre-eclampsia and its complications. Cochrane Database Syst Rev 2007;(2):CD004659.

22. Sibai BM, el-Nazer A, Gonzalez-Ruiz A. Severe preeclampsia-eclampsia in young primigravid women Subsequent pregnancy outcome and remote prognosis. Am J Obstet Gynecol 1986;155:1011-1016. [http://dx.doi.org/10.1016/0002-9378(86)90336-4]

23. Vikse BE, Irgens L M Leivestad T et al. Preeclampsia and the risk of end-stage renal disease. N Engl Vikse BE, Irgens L M, Leivestad T, et al. Preeclampsia and the risk of end
Med 2008;359(8):800-809. [http://dx.doi.org/10.1056/NEJMoa0706790]

24. Jones DC, Hayslett JP. Outcome of pregnancy in women with moderate or severe renal insufficiency. N Engl I Med 1996;335:226-232. [http://dx.doi.org/10.1056/NEJM199607253350402]

25. Hou S. Pregnancy in chronic renal insufficiency and end-stage renal disease. Am I Kidney Dis 1999;33:235-252. [http://dx.doi.org/10.1016/S0272-6386(99)70296-9]

6. Katz AI, Davison JM. Hayslett JP, et al. Pregnancy in women with kidney disease. Kidney In 1980;18(2):192-206. [http://dx.doi.org/10.1038/ki.1980.128]

7. Leavey SF, Weitzel WF. Endocrine abnormalities in chronic renal failure. Endocrinol Metab Clin North Am 2002;31:107-111. [http://dx.doi.org/10.1016/S0889-8529(01)00006-8]

28. Krane NK. Acute renal failure in pregnancy. Arch Intern Med 1988;148:2347-2357.

29. Grünfeld J-P, Pertuiset N. Acute renal failure in pregnancy. Am J Kidney Dis 1987;9:359-362. [http:// dx.doi.org/10.1016/S0272-6386(87)80137-3]

30. Rossing K, Jacobsen P, Hommel E, et al. Pregnancy and progression of diabetic nephropathy. Diabetologia 2002;45(1):36-41. [http://dx.doi.org/10.1007/s125-002-8242-4]

31. Mathiesen ER, Ringholm L, Feldt-Rasmussen B, et al. Obstetric nephrology: Pregnancy in women with diabetic nephropathy - the role of antihypertensive treatment. Clin J Am Soc Nephrol 2012;7(12):20812088. [http://dx.doi.org/10.2215/CIN.00920112]
32. Tandon A, Ibanez D, Gladman DD, Urowitz MB. The effect of pregnancy on lupus nephritis. Arthritis Rheum 2004;50:3941-3946. [http://dx.doi.org/10.1002/art.20638]

33. Montan S, Anandakumar C, Arulkumaran S, et al. Effects of methyldopa on uteroplacental and fetal . Montan S, Anandakumar C, Arulkumaran S, et al. Effects of methyldopa on uteroplacental and fetal
hemodynamics in pregnancy-induced hypertension. Am J Obstet Gynecol 1993;168:152-156. [http:// dx.doi.org/10.1016/S0002-9378(12)90905-9]

34. Sibai BM, Mabie WC, Shamsa F, et al. A comparison of no medication versus methyldopa or labetalol in chronic hypertension during pregnancy. Am J Obstet Gynecol 1990;162:960-966. [http://dx.doi. org/10.1016/0002-9378(90)91297-P]

35. Lindow SW, Davies N, Davey DA, Smith JA. The effect of sublingual nifedipine on uteroplacental blood flow in hypertensive pregnancy. Br J Obstet Gynaecol 1988;95:1276-1281. [http://dx.doi. org/10.1111/j.1471-0528.1988.tb06818.x]

36. Sibai BM, Mabie WC, Shamsa F, Villar MA, Anderson GD. A comparison of no medication versus methyldopa or labetalol in chronic hypertension during pregnancy. Am J Obstet Gynecol 1990;162(4):960-967. [http://dx.doi.org/10.1016/0002-9378(90)91297-P]

37. Collins R, Yusuf S, Peto R. Overview of randomised trials of diuretics in pregnancy. Br Med J (Clin Res Ed) 1985;290:17-23. [http://dx.doi.org/10.1136/bmj.290.6461.17]

38. Pryde $P G$, Sedman $A B$, Nugent $C E$, Barr $M$ Jr. Angiotensin-converting enzyme inhibitor fetopathy. J Am Soc Nephrol 1993;3:1575-1582.

39. Cooper WO, Hernandez-Diaz S, Arbogast PG, et al. Major congenital malformations after first-trimester exposure to ACE inhibitors. N Engl J Med 2006;354:2443-2451. [http://dx.doi.org/10.1056/NEJMoa055202] 40. Saji H, Yamanaka M, Hagiwara A, Jjiri R. Losartan and fetal toxic effects. Lancet 2001;357(9253):363. [http://dx.doi.org/10.1016/S0140-6736(00)03648-5 